\title{
Prevalence and Risk Factors Associated with Anaemia Amongst Adolescent Girls Attending in Pediatrics OPD of Nepalgunj Medical College
}

\author{
Ahmad S
}

\begin{abstract}
Background: The habits that children inculcate during adolescence remains with them throughout the life. Anaemia is one of the most prevalent health conditions amongst the Girls residing in developing countries. The present study was conducted with the aim to determine the prevalence and risk factors associated with anaemia amongst adolescent girls attending in paediatrics OPD of Nepalgunj Medical College. Materials and methods: The present cross sectional study was performed for a period of one year (February 2016 - March 2017). This study was conducted amongst the girls attending to the Paediatrics department of Nepalgunj Medical College and Teaching Hospital, Nepalgunj. The study included all the girls aged between 10-19 years. Each Girls underwent physical examination under trained supervision to record sign of anaemia like pallor. Body mass index of all the subjects was also calculated. The data obtained was arranged in a tabulated form and analysed using SPSS software. Results: A total of 200 girls were enrolled in this study. The mean age of the study sample was $21.10+/-10.67$ years. Majority of the early adolescents (68.5\%) had anaemia. Least number (36\%) of anaemic patients was seen in mid adolescence. There were $47.5 \%$ girls in late adolescence that showed signs of anaemia. There were $47.9 \%$ Girls who had passage of worms and $50.1 \%$ had no worm infestations. Majority (63.5\%) of non anaemic Girls were in their post menarche stage. Conclusion: There were $52 \%$ of the girls who were anaemic in our study. The proportion of undernourished girls were significantly higher, therefore body mass index significantly affects anaemia.
\end{abstract}

Key words: Adolescence, anaemia, haemoglobin

\section{INTRODUCTION}

Adolescents are defined as Girls who are aged between 10 to 19 years of age; this definition is as per World health organisation $^{1}$. It is regarded as transition from childhood to adulthood. Out of 2.7 million population of Nepal, there are $23 \%$ adolscenst ${ }^{2,3}$. The habits that children inculcate during adolescence remains with them throughout the life. At this stage a child is at his cross roads and they make important and crucial decisions during this stage. According to World Health Organisation, anaemia is defined as a condition in which haemoglobin falls to less than $11 \mathrm{~g} / \mathrm{dl}$ for Girls aged less than 6 years and haemoglobin less than $12 \mathrm{~g} / \mathrm{dl}$ for Girls more than 6 years ${ }^{4}$. Anaemia is one of the most prevalent health problem amongst the Girls residing in developing countries ${ }^{5}$. The epidemiology of anaemia varies amongst different nations according to ecology and sociocultural environment. As per a Nepalese survey that was conducted in 2006, there were $48 \%$ subjects who were anaemic between the age group of 6-59 months ${ }^{6}$. According to some other studies there is $42-60 \%$ population of Nepal was anaemic ${ }^{7,8}$. There have not been much surveys concentrating only on adolescent subjects especially girls. The availability of iron is a crucial factor amongst girls especially in the reproductive age group. Due to this reason special attention needs to pay to girls of this age group. Therefore the present study was conducted with the aim to

\section{Address for correspondence:}

Dr. Shakil Ahmad

Department of Pediatrics

Nepalgunj Medical College Teaching Hospital

Nepalgunj, Banke, Nepal

Email: sheikh_shak@yahoo.com determine the prevalence and risk factors associated with anaemia amongst adolescent girls attending in paediatrics OPD of Nepalgunj Medical College.

\section{MATERIALS AND METHOD}

The present cross sectional study was carried out for a period of one year (February 2016- March 2017). This study was conducted amongst the girls attending to the Paediatrics department of Nepagunj Medical College and Teaching Hospital, Nepalgunj, Banke. The study included all the girls aged between 10-19 years. Unmarried, non lactating girls reporting to the hospital due to any illness were included in the study. Ethical committee clearance was obtained prior to initiation of the study. All the Girls were informed about the study and a written consent was obtained from institute's ethical committee. Girls with Thalassemia, chronic illness or any malignant disorder were excluded from the study. Patient's demographic details, education, diet, menstrual history, medical condition were recorded in a predesigned Performa. Each subject underwent physical examination under trained supervision to record sign of anaemia like pallor. Body mass index of all the subjects was also calculated.

Procedure- under complete aseptic condition, $5 \mathrm{ml}$ of venous blood was withdrawn from the anticubital vein and stored in EDTA vial. Haemoglobin estimation was done using cyanmethaemoglobin method. Recording of anaemia was done as per the World Health organisation protocol. The data obtained was arranged in a tabulated form and analysed using SPSS software.Chisquare test and Man Whitney test were applied as a test of significance. Probability value of less than 0.05 was considered significant. 


\section{RESULTS}

A total of 200 girls were enrolled in the study. The mean age of the study sample was $21.10+/-10.67$ years. Table I shows the prevalence of anaemia. There were $104 \mathrm{Girls}$ (52\%) in which the level of haemoglobin was less than $12 \mathrm{~g} / \mathrm{dl}$. Approximately $48 \%$ Girls ( $n=96$ ) had haemoglobin more than $12 \mathrm{~g} / \mathrm{dl}$.

Table II shows age wise distribution of the anaemic patients. Majority of the early adolescents (68.5\%) had anaemia. Least number (36\%) of anaemic patients was seen in mid adolescence. There were $47.5 \%$ girls in late adolescence that showed signs of anaemia. There were52.5\% Girls in late adolescence and $64 \%$ Girls in mid adolescence who were not anaemic.

Out of the anaemic population, there were $67.3 \%$ vegetarian and $32.6 \%$ non vegetarian. There were $51.9 \%$ subjects who had passage of worms and $48.1 \%$ had no worm infestations.
Majority (64.4\%) of anaemic subjects were in their premenarcheal stage. There were $48.1 \%$ who were undernourished, $38.5 \%$ subjects had normal BMI and rest were overweight. Out of the non anaemic population, there were $23.9 \%$ vegetarian and $76.1 \%$ non vegetarian. There were $47.9 \%$ Girls who had passage of worms and $50.1 \%$ had no worm infestations. Majority (63.5\%) of non anaemic Girls were in their post menarche stage. There were $27 \%$ who were undernourished, 52.1\% Girls had normal BMI and rest were overweight. There was a significant difference in BMI amongst anaemic and non anaemic Girls.

\section{DISCUSSION}

Approximately 1 billion people in the world are iron deficient, nutritional deficiency is the major cause of anaemia ${ }^{9}$. There is scarcity of data on the prevalence of anaemia amongst the adolescent girls. As per the present study, there were $52 \%$ subjects who were anaemic. In the studies conducted by Chaturvedi et al and Ahmed $\mathrm{F}$ et al the prevalence of anaemia was 40 to $60 \%{ }^{10,11}$. As per a study conducted by Saroj K et al ${ }^{12}$

\begin{tabular}{|l|c|c|}
\hline HAEMOGLOBIN & FREQUENCY & PERCENTAGE \\
\hline$<12 \mathrm{~g} / \mathrm{dl}$ & 104 & 52 \\
\hline$>12 \mathrm{~g} / \mathrm{dl}$ & 96 & 48 \\
\hline
\end{tabular}

Table I: Prevalence of anaemia

\begin{tabular}{|l|c|c|c|}
\hline \multirow{2}{*}{ AGE GROUP } & \multirow{2}{*}{ FREQUENCY } & \multicolumn{2}{|c|}{ ANEMIA } \\
\cline { 3 - 4 } & & PRESENT & ABSENT \\
\hline Early adolescent & 70 & $48(68.5 \%)$ & $22(31.4 \%)$ \\
\hline Mid adolescent & 50 & $18(36 \%)$ & $32(64 \%)$ \\
\hline Late adolescent & 80 & $38(47.5 \%)$ & $42(52.5 \%)$ \\
\hline
\end{tabular}

Table II: prevalence of anaemia amongst different age groups

\begin{tabular}{|l|c|c|c|}
\hline CHARACTERSTICS & $\begin{array}{c}\text { ANEMIC } \\
\mathrm{N}=\mathbf{1 0 4}\end{array}$ & $\begin{array}{c}\text { NON ANEMIC } \\
\mathrm{N}=96\end{array}$ & P VALUE \\
\hline Diet consumed & & & $>0.05$ \\
\hline Vegetarian & $70(67.3 \%)$ & $23(23.9 \%)$ & \\
\hline Non vegetarian & $34(32.6 \%)$ & $73(76.1 \%)$ & $>0.05$ \\
\hline Passage of worms & & & \\
\hline Yes & $54(51.9 \%)$ & $46(47.9 \%)$ & \\
\hline No & $50(48.1 \%)$ & $50(50.1 \%)$ & $>0.05$ \\
\hline Menstrual status & & & \\
\hline Pre menarche & $67(64.4 \%)$ & $35(36.5 \%)$ & \\
\hline Post menarche & $37(35.6 \%)$ & $61(63.5 \%)$ & $<0.05$ \\
\hline Nutritional status & & & $>0.05$ \\
\hline Undernourished & $50(48.1 \%)$ & $26(27 \%)$ & $>0.05$ \\
\hline Normal & $40(38.5 \%)$ & $50(52.1 \%)$ & \\
\hline overweight & $14(13.4 \%)$ & $14(14.6 \%)$ & \\
\hline
\end{tabular}

Table III: prevalence of anaemia according to personal characteristics 
there were $42.4 \%$ Girls at school of Morang, $31.6 \%$ Girls at school of Udaipur, $45.3 \%$ children at school of Bhojpur and $34.8 \%$ in school of llam district that were anaemic. The increased prevalence of anaemia amongst the girls is chiefly due to deficiency of iron. In our study, out of the anaemic population, there were $67.3 \%$ vegetarian and $32.6 \%$ non vegetarian. There were $51.9 \%$ Girls who had passage of worms and $48.1 \%$ had no worm infestations. Majority (64.4\%) of anaemic Girls were in their premenarcheal stage. There were $48.1 \%$ who were undernourished, $38.5 \%$ Girls had normal BMI and rest were overweight.

Out of the non anaemic population, there were $23.9 \%$ vegetarian and $76.1 \%$ non vegetarian. There were $47.9 \%$ Girls who had passage of worms and $50.1 \%$ had no worm infestations. Majority (63.5\%) of non anaemic Girls were in their post menarche stage. There were $27 \%$ who were undernourished, $52.1 \%$ Girls had normal BMI and rest were overweight. There was a significant difference in BMI amongst anaemic and non anaemic subjects. In a study conducted by Gupta et al ${ }^{13}$ Body mass index was not significantly associated with anaemia amongst the girls. As per a study conducted by $P$. Kanodia et $\mathrm{al}^{14}$ majority of the under nourished girls were anaemic similar to our study. As per our study, majority of the early adolescents (68.5\%) had anaemia. Least number (36\%) of anaemic patients was seen in mid adolescence. There were $47.5 \%$ girls in late adolescence that showed signs of anaemia. There were $52.5 \%$ Girls in late adolescence and $64 \%$ subjects in mid adolescence who were not anaemic. In a study conducted by Verma et $\mathrm{al}^{15}$ amongst children of Punjab, India, there were higher proportion of vegetarian girls who were anaemic as compared to non vegetarian girls. In our study, worm infestations were another major cause of anaemia. Iron supplementation with regular deworming sessions can help reduce the incidence of anaemia amongst girls. Community based programs should be initiated by the authorities to reduce its occurrence. Students should also be educated towards importance of nutrition in daily life.

\section{CONCLUSION}

There were $52 \%$ of the girls who were anaemic in our study. The proportion of undernourished girls were significantly higher, therefore body mass index significantly affects anaemia occurrence. Educational programmes and medical checkups should be conducted at regular interval at both institute and community to encourage an anaemia free nation.

\section{REFERENCES}

1. WHO. Young People's Health. A Challenge for Society. WHO Technical Report Series no 731, WHO, Geneva, Switzerland 1986.

2. WHO. Country Health Indicators. Www. who.int/ who sis/ country/indicators.cfm?-- npl (accessed on 11/9/07).

3. Central Bureau of Statistics. Population Census 2001 National Report. HMG/Nepal National Planning Commission Secretariat Central Bureau of Statistics in collaboration with UNFPA Nepal, Kathmandu 2002.
4. Demaeyer EM. Preventing and Controlling Iron Deficiency Anaemia through Primary Health Care. Geneva, World Health Organization, 1998-99.

5. de Benoist B, Lean ME, Egli I, et al. Worldwide Prevalence of Anaemia 1993-2005, WHO Global Database on Iron Deficiency and Anaemia. Geneva: World Health Organization, 2008.

6. Nepal Demographic and Health Survey 2006. Kathmandu, Nepal: Ministry of Health and Population, New ERA, and Macro International Inc, 2007.

7. Rikimaru T, Joshi N, Pandey S. Prevalence of anaemia and its relevant factors among High School girls of Kathmandu ValleyNepal. Nutrition Section, Child Health Division, $\mathrm{MOH}, \mathrm{WHO}$ and JICA, Kathmandu, Nepal 2003. PMID: PMC1746799.

8. Regime SC, Adhikari RK. A Study on the factors influencing nutritional status of adolescent girls. New ERA, Kathmandu, Nepal 1994. PMID: 8058860.

9. DeMaeyer E, Adiels-Tegman M. The Prevalence of anaemia in the world. World Health Stat Quarter 1985; 38: 302-16.

10. Chaturvedi S, Kapil U, Gnanasekaran N, Sachdev H.P.S, Pandey R.M and Bhanti T. Nutrient intake amongst girls belonging to poor socio-economic group of rural area of Rajasthan. Indian Paediatrics. 1996; 33:197-202. PMID: 8772838.

11. Ahmed F, Khan MR, Islam M, Kabir I, Fuchs GJ. Anaemia and iron deficiency among adolescent school girls in peri-urban Bangladesh. Eur J Clin Nutr. 2000; 54: 678-683. DOI: 10.1038/sj.ejcn.1601073. PMID: 11002378.

12. Khatiwada S, Gelal B, Gautama S, Tamang MK, Shaky PR, Lamsal M, Baral N. Anaemia among school children in eastern Nepal. Journal of tropical paediatrics. 2015 Mar 30; 61(3):231-3.

13. Shah BK, Gupta P. Anaemia in adolescent girls: a preliminary report from semi-urban Nepal. Indian Paediatric. 2002 Dec; 39(12):1126-30.

14. Kanodia P, Bhatt M, Singh RR, Bhatt NK, Shah GS. A study of anaemia among adolescent girls in eastern part of Nepal. Journal of College of Medical Sciences-Nepal. 2016 Mar 31; 12(1):19-22.

15. Verma M, Chhatwal J, Kaur G. Prevalence of anaemia among urban school children of Punjab. Indian Paediatrics. 1999; 36:1181-6. 